\title{
UMA MULHER SÍRIA COMO IMPERATRIZ ROMANA: CONSIDERAÇÕES SOBRE ELE- MENTOS DO PODER E DA IDENTIDADE CULTURAL DE JÚLIA DOMNA (SÉCULO III $\mathrm{EC})^{1}$
}

\author{
Semiramis Corsi Silva ${ }^{2}$
}

\begin{abstract}
Resumo: A partir de final do século II EC, uma nobre família da cidade de Emesa, na Síria, ascende na administração imperial romana por meio do casamento de Júlia Domna com o general Septímio Severo, feito imperador anos mais tarde, em 193. A partir de então, o poder dos próximos imperadores romanos, membros da dinastia dos Severos (193-235), será transmitido de forma matrilinear. Depois de Júlia Domna, sua irmã Júlia Mesa terá grande poder sob a política e o governo imperial dos netos Heliogábalo (218222) e Severo Alexandre (222-235). Da mesma forma, tiveram poder no governo romano Júlia Soêmia e Júlia Mamea, mães de Heliogábalo e Severo Alexandre, respectivamente. Nesse sentido, Júlia Domna teve uma importância fundamental na continuação dinástica, além de grande destaque nos governos de seu marido Septímio (193-211) e de seu filho Caracala (211-217). Este estudo pretende abordar elementos do poder de Júlia Domna, apresentando suas possibilidades de ação enquanto imperatriz. Viso, da mesma forma, fazer uma análise sobre elementos da identidade cultural de Júlia Domna em relação às críticas negativas à imperatriz em textos do contexto romano.
\end{abstract}

Palavras-chaveः Império Romano; dinastia dos Severos; Júlia Domna; Emesa.

1 Dedico este texto à minha mãe Ruth Corsi e à Profa. Dra. María José Hidalgo de la Vega (Universidad de Salamanca), mulheres feministas que me ensinaram tanto sobre o tema, uma de forma prática no cotidiano de minha educação enquanto sua filha, a outra com suas orientaçóes durante meu estágio em Salamanca entre 2012 e 2013 e com seu livro Las imperatrizes romanas (2012), inspiração para este texto. No entanto, ainda que traga uma postura feminista da autora, este texto é marcado pelo comprometimento com a análise das diferenças e descontinuidades históricas, o que defendo ser possível de fazer sem deixar de conciliar minha postura política contemporânea. Devo destacar também que este artigo faz parte da pesquisa pessoal da autora dentro do projeto de pesquisa guarda-chuva Barbaridade: identidades e alteridades em representaçóes do outro por escritores romanos. O projeto conta com apoio da Fundação de Amparo à Pesquisa do Estado do Rio Grande do Sul - FAPERGS, através do Edital 01/2017- Auxílio Recém-doutor - ARD.

2 Professora do Departamento de História e do Programa de Pós-graduação em História da Universidade Federal de Santa Maria - UFSM. Doutora em História pela Universidade Estadual Paulista - UNESP/Franca. Pesquisadora do G.LEIR/UNESP-Franca, do NEAM/UNESP, do ATRIVM/UFRJ, do NECH/PUC-GO e do LEIR/USP. Pesquisadora e Coordenadora do GEMAM/UFSM e do Grupo de Trabalho História Antiga da ANPUH/RS - GTHA-RS (gestão 2016-2018).E-mail: semiramiscorsi@yahoo.com.br 


\section{INTRODUÇÃo}

Em nossa contemporaneidade temos visto a ascensão de algumas mulheres a importantes cargos político-administrativos nos países considerados ocidentais. É possível citar como exemplos mais recentes: Angela Merkel, chanceler da Alemanha desde 2005, Cristina Kirchner, presidenta da Argentina entre 2007 e 2015 e, claro, Dilma Rousseff, presidenta do Brasil de 2011 até seu afastamento por um golpe político em 2016.

A ascensão política dessas mulheres está ligada a um longo processo histórico de lutas feministas e transformações de ordem política, social e cultural. No entanto, é possível perceber que as mesmas receberam, e ainda recebem, críticas de ordens diversas em suas atuações públicas. Tais críticas não estão desligadas de reflexões contrárias a elementos de suas propostas políticas e condutas administrativas, mas também, é preciso frisar, dizem respeito às suas atuaçóes por serem mulheres em meio a uma sociedade que ainda tem bases históricas e culturais patriarcais e misóginas, especialmente no âmbito político-administrativo do Estado. ${ }^{3}$

Diferentemente da contemporaneidade, as mulheres aristocratas sempre tiveram importância na manutenção do poder imperial romano, assumindo papeis políticos de relevância, ainda que sem cargos estabelecidos e estando ao lado - às vezes à frente, embora não seja algo presente nas titulações de um homem ocupante de cargos político-administrativos. $\mathrm{O}$ poder dessas mulheres, por sua vez, não estava marcado por lutas feministas de forma alguma, mas pelas famílias nas quais elas haviam nascido e pelo peso que o fator familiar e as alianças baseadas na amicitia e no parentesco tinham na manutenção da ordem e da política romana. ${ }^{4}$

3 Um exemplo de misoginia que ficou bem famoso pautando as críticas políticas à Dilma Rousseff foi a capa, seguida de matéria, da revista Isto É de abril de 2016. Na capa e matéria, o jornalismo da revista alude à perda de condições emocionais da presidenta, ilustra um estereótipo médico criado como um saber/poder em torno da patologização dos ânimos da mulher, tida, então, como propensa a ser louca e histérica. Dilma, na matéria, é mostrada como uma mulher descontrolada que quebra coisas ao seu redor e não tem a menor condição de governar um país. Retórica misógina bem conhecida que lembra exemplos históricos de construções sobre rainhas europeias da Época Moderna. Em uma rápida busca pela internet, é possível ver que capas como a referida de Dilma Rousseff estão por toda parte na impressa internacional quando tratam de críticas a mulheres que ocupam posições e cargos político-administrativos.

4 Entendo que amicitia "não era somente um laço subjetivo de afeição, mas também uma ligação objetiva baseada na assistência mútua e na fides, isto é, na lealdade entre os amici." Na antiga Roma e no Império Romano, "Amicitia, amicus, auctoritas, fides são termos que fazem parte do vocabulário político e quando unidos formam a base das relações de patronato" (VENTURINI, 2001, p. 216). 
Dessa forma, é preciso perceber que códigos de parentesco e elementos de gênero foram, e ainda são, essenciais no fazer político, fazem parte dele sem que a política seja uma dimensão autônoma e sem que o gênero seja algo menor. Ainda que isso pareça algo claro, conforme muitos estudos históricos têm mostrado, diversos historiadores e historiadoras contemporâneos ainda têm muita dificuldade, ou mesmo falta de vontade, em reconhecer.

Também de forma diferente das mulheres a assumirem cargos políticoadministrativos contemporâneos, o importante poder que as mulheres aristocratas romanas possuíam, em geral, era mantido nos bastidores das ações em termos de cargos assumidos e títulos. ${ }^{5}$ Diante disso, para analisar a imperatriz romana Júlia Domna, estou pensando o poder numa perspectiva foucaultiana, em que tal elemento aparece pulverizado de formas diversas, concordando com María José Hidalgo de la Vega (2012, p. 19), por meio de saberes, construções discursivas diversas e também elementos da prática política de cada contexto, como o caso aqui analisado.

Um fator em comum entre Antiguidade e Contemporaneidade, no entanto, parece ter sido o fato de que o poder político das mulheres era bastante criticado pelos escritores homens quando lhes convinham, ressaltando, conforme suas necessidades de criticar tais mulheres, justamente questões relacionadas ao gênero. Ou seja, quando determinado escritor do Império Romano necessitava criticar certos elementos da política que escapavam aos seus interesses pessoais ou de grupo, se houvesse mulheres em meio às ações, ele usava desse fator para tecer suas críticas, muitas vezes masculinizando-as e, da mesma forma, afeminando governantes criticados. ${ }^{6}$

As imperatrizes e demais mulheres aristocratas das casas imperiais romanas estão por todos os textos que tratam das histórias do Principado Romano. Tácito, Suetônio, Dião Cássio e Herodiano são exemplos de escritores do período que nos deixaram seus relatos masculinos sobre elas. Lívia, as Agripinas, Messalina, Domicia Longina, Pompeia Plotina, Faustina, Júlia Domna, Júlia Mesa são algumas dessas mulheres.

5 Sigo, assim, a percepção de Paul Veyne (1983) sobre a importância de a historiografia ser tomada como um inventário das diferenças. Veyne nos convida para perceber a História a partir da perspectiva da Sociologia. Sendo assim, a História pode ser definida como o inventário explicativo não dos homens ou das sociedades, mas daquilo que há de social no homem, ou, mais precisamente, das diferenças manifestadas pelo aspecto social. Caminhando junto aos aportes da Sociologia, a História, para Veyne, passa a ser interpretativa e problemática, mostrando que não há leis de desenvolvimento cabíveis a todo e qualquer contexto, mas diferenças dentro do que há de estruturas.

6 Sobre o assunto, sugiro a leitura de SILVA, 2018. 
Tais personagens ora eram tidas como modelo de mulheres virtuosas por cumprirem o papel que era esperado delas enquanto aristocratas da casa imperial, a importante questão da maternidade, fator fundamental para a sucessão e legitimação do poder. Ora, por outro lado, eram tidas como infames por fugirem do modelo patriarcal e aristocrático ao assumirem poderes excessivos ou ao se envolverem em relaçóes que ameaçavam elementos da ordem imperial, marcada pelo cumprimento do mos maiorum. ${ }^{7}$ Ressalto, assim, que em uma análise das mulheres das casas imperiais romanas é preciso cruzar, além das análises de construções sobre papeis atribuídos aos gêneros, a análise da ordem social que estas mulheres pertenciam.

As mulheres citadas acima têm sido objeto de importantes pesquisas dentro dos debates sobre História das Mulheres e dos Estudos de gênero. Um grupo de mulheres das casas imperiais do Principado, em específico, tem me chamado atenção, diz respeito às mulheres da casa severiana: Júlia Domna, Júlia Mesa, Júlia Soêmia e Júlia Mamea. A razão pela qual elas despertaram meu interesse diz respeito ao fato de que, além de proporcionarem interessantes reflexões sobre questões de gênero e poder romano, o estudo sobre as mulheres severianas possibilita a reflexão sobre elementos de identidade cultural e a ordem romana por elas serem sírias.

Por questóes de recorte do objeto, neste artigo analisarei as representaçóes de Júlia Domna em textos de viés aristocrático escritos em seu contexto e que chegaram para nós, pensando gênero, relações sociais e identidade cultural. Buscarei levantar alguns questionamentos sobre os meios que mulheres como Júlia Domna podiam atuar politicamente e também como elementos de sua identidade cultural foram utilizados em críticas a sua atuação. Ressaltarei, por fim, a complexidade das representaçóes da imperatriz em meio ao seu papel político junto aos aristocratas escritores de textos e como isso reverberou na construção discursiva sobre ela. Diante disso, para melhor compreender a imagem de Júlia Domna, faz-se necessário, inicialmente, apresentar algumas características da região de onde ela veio.

\section{Júlia Domna e a Regiño de Emesa}

Júlia Domna era filha de Caio Júlio Bassiano, alto-sacerdote da divindade solar conhecida tradicionalmente como Elagabal e membro de uma

\footnotetext{
7 De acordo com Maria Regina Bustamante (2006, p. 112), mos maiorum eram os costumes e valores ancestrais reafirmados de forma contundente como forma de estabelecimento de um discurso de identidade e poder.
} 
nobre família da cidade síria de Emesa (atual Homs, na Síria). Pelos nomes atribuídos a eles que foram legados pela documentação textual e material greco-romana, é possível ver que a família havia recebido cidadania romana e unida à importante gens Iulia. Esse fato marca que, muito provavelmente, membros da família de Júlia Domna haviam recebido cidadania romana na época de Júlio César ou dos primeiros imperadores Júlio-claudianos: Augusto (27 AEC-14 EC), Tibério (14-37) e Calígula (37-41).

É sabido que no período republicano e no Principado as mulheres romanas não recebiam nome individual, apenas o nome da gens ou da família a qual pertenciam com terminação feminina, acrescido de algum tipo de apelido que as distinguisse (FINLEY, 1991, p. 151). ${ }^{8}$ Assim, o nome dessa importante mulher síria que ficou na tradição é Júlia Domna.

Ainda que o nome Júlia da imperatriz traga um elemento de sua relação com Roma, sua denominação também mostra outro importante aspecto a ser considerado sobre ela e sobre a dinastia que dela descenderá, a manutenção de elementos culturais siríacos. Assim, conforme Hidalgo de la Vega (2012, p. 134):

Quanto ao segundo nomen, Domna, apesar das tentativas de especialistas em relacionarem seu nome como abreviatura de domina, por sua familiaridade aparente com o latim [...] A origem do nome se deve à forma arábica Dumayana e está relacionada com a palavra que designa a cor negra. Sua irmã Júlia Mesa também tem um nome árabe e uma das filhas dessa tomou o nome feminino do dinasta Sobaemus, Soemia. A outra manteve o nome semítico, Mamea, seguindo o costume sírio de que as mulheres dessa família manteriam o nome árabe original.

Ana Teresa Marques Gonçalves (2003, p. 332) traz outra significação siríaca para o termo Domna. Segundo Gonçalves, a imperatriz passou a ter essa nomenclatura devido a um horóscopo que havia recebido, dizendo que ela estava predestinada a ser esposa de um soberano, sendo Domna a transposição da palavra síria Martha, que significa senhora, mestra. $^{9}$

8 Por este elemento é possível ver como as mulheres romanas eram classificadas como uma espécie de propriedade de sua família. Conforme Moses Finley (1991, p. 151-152), "é como se os romanos quisessem sugerir, não muito sutilmente, que as mulheres não eram ou não deveriam ser indivíduos genuínos, mas apenas frações de uma família."

9 Ainda que o termo Martha possa ser colocado como sírio de forma generalizada, acredito que o mais correto é referir-se a ele como aramaico. Sobre a expansão aramaica pelo Levante e pela complexa região geograficamente chamada de Síria, bem como sobre quem foram os arameus, sugiro a leitura do capítulo Os Arameus na Síria e na Mesopotâmia, da obra Antigo Oriente (2016), de Mário Liverani. 
Independente do significado em si do termo, há uma corrente de historiadores que defendem que a palavra Domna ligava a imperatriz aos elementos siríacos de Emesa. Nesse sentido, mesmo que Júlia Domna e as demais mulheres sírias da casa severiana não tenham tido um nome próprio (praenomen); conforme a cultura romana mantinha em relação aos homens, trazendo todas elas o nome (nomen) Julia, que marcava a ligação da família à cultura romana; vemos que as mesmas conservaram na denominação um elemento cultural de sua região.

Sobre suas tradições siríacas, cumpre ressaltar que, segundo informações fornecidas por Barbara Levick (2007, p. 6-9), o que chamamos de antiga Síria não se configurava como uma unidade política propriamente, mas como uma variedade de reinos entre o Egito e as potências imperialistas do norte, sendo um cenário de conflito entre tais poderes. A arqueologia ainda não conseguiu saber ao certo a fundação do assentamento urbano de Emesa, a cidade de onde vem Júlia Domna. A história da região anterior ao período helenístico é bastante desconhecida. Há vestígios que mostram que o assentamento de Emesa é anterior ao século I AEC, provavelmente do século II AEC, tendo feito parte do Império Selêucida. Com o declínio do Império Selêucida, houve uma fragmentação de reinos árabes na região, dos quais Emesa foi um deles. Mas, antes disso, a região fez parte do Império Persa, período do qual se sabe muito pouco sobre toda a região da Síria (MILLAR, 1987, p. 112).

A arqueologia detecta em Emesa uma mistura de fortes influências semíticas (árabes aramaicas e fenícias) e das culturas mesopotâmicas. ${ }^{10}$ Conforme Fergus Millar (1987, p. 128), Cícero (106-43 AEC) chamou o reino de Emesa, independente no contexto do orador romano, de árabe. Temos também que o nome de um importante governante local da época de Cícero, Sampsigeramus, vem do termo árabe shemesh, que significava sol. Entretanto, Millar chama atenção para percebermos que a referência à famosa divindade solar de Emesa, Elagabal, parece não ter ligação com essa expressão árabe, podendo ter, na verdade, uma influência fenícia significativa.

Conforme Millar (1987, p. 128-129), uma antiga inscrição encontrada próxima ao que foi Emesa traz a expressão 'Ilh'gbl', referindo-se a Elaha Gabal, deus da montanha. Somado a isso, Millar observa que Herodiano (História do Império Romano, V, 3, 4-5) refere-se ao nome de Elagabal como sendo fenício. Da mesma forma, o escritor Heliodoro, nascido em Emesa, refere a si próprio como fenício em sua obra Etiópica. Acrescento às observações de 
Millar a informação de que, pelos relatos bíblicos, Baal, possível influência para Elagabal, era uma divindade cultuada na região próxima da antiga Judeia e extremamente criticada pelos escritores do Antigo Testamento (Nùmeros 25: 1-3; 1 Reis 18: 25-28, 18: 40; Jeremias 19:5).

Como não há referências ao culto de Elagabal do período helenístico em Emesa, Millar, então, levanta a possibilidade de o culto que a família de Júlia Domna levou a Roma ser produto dos contatos dos árabes em suas incursões pelas rotas comerciais para dentro das franjas do deserto. Portanto, talvez a implantação do culto a Elagabal em Emesa, ou pelo menos a ressignificação de elementos cultuais e seu nome, advenha de contatos com os fenícios ou com outras tradiçóes de fora da cidade ligadas a uma divindade relacionada com a ideia de um Senhor da Montanha. Tal divindade emesense, em minha conclusão, pode ter seu nome e/ou culto relacionados a elementos da antiga divindade criticada no Antigo Testamento. Assim, devemos considerar uma forte presença fenícia nesse importante elemento político-cultural da cidade.

Sobre as influências gregas, mesmo tendo feito parte do Império Selêucida, os vestígios tendem a apresentar uma ausência de força nos elementos gregos anteriores ao período romano em Emesa. Portanto, o elemento grego ficará mais forte em Emesa após a região passar a ser parte do Império Romano, sendo a cultura grega fundamental da manutenção do poderio imperial romano no Oriente. Em relação ao idioma emesense do período romano, "esse era provavelmente uma mistura de aramaico e grego, ocasionalmente falava-se latim e podemos ter certeza, que ouviríamos aramaico dentro das casas particulares" (LEVICK, 2007, p. 15-20).

Já as influências culturais romanas do período imperial são encontradas especialmente na arquitetura. Em relação ao expansionismo de Roma, os habitantes do distrito de Emesa, governados, então, por uma forte dinastia árabe aramaica na época republicana, souberam negociar com os poderes e com os conflitos entre os generais romanos, realizando casamentos como forma de alianças. Desse período, por vezes, o reino de Emesa dominou algumas regióes vizinhas como Arethusa, Sophene e Arca (LEVICK, 2007, p. 09). Emesa tornou-se parte da província romana da Síria na época do imperador Domiciano (81-96), aparecendo o poder da antiga dinastia real na documentação até a época de Antonino Pio (138-161) (HIDALGO DE LA VEGA, 2012, p. 132). 

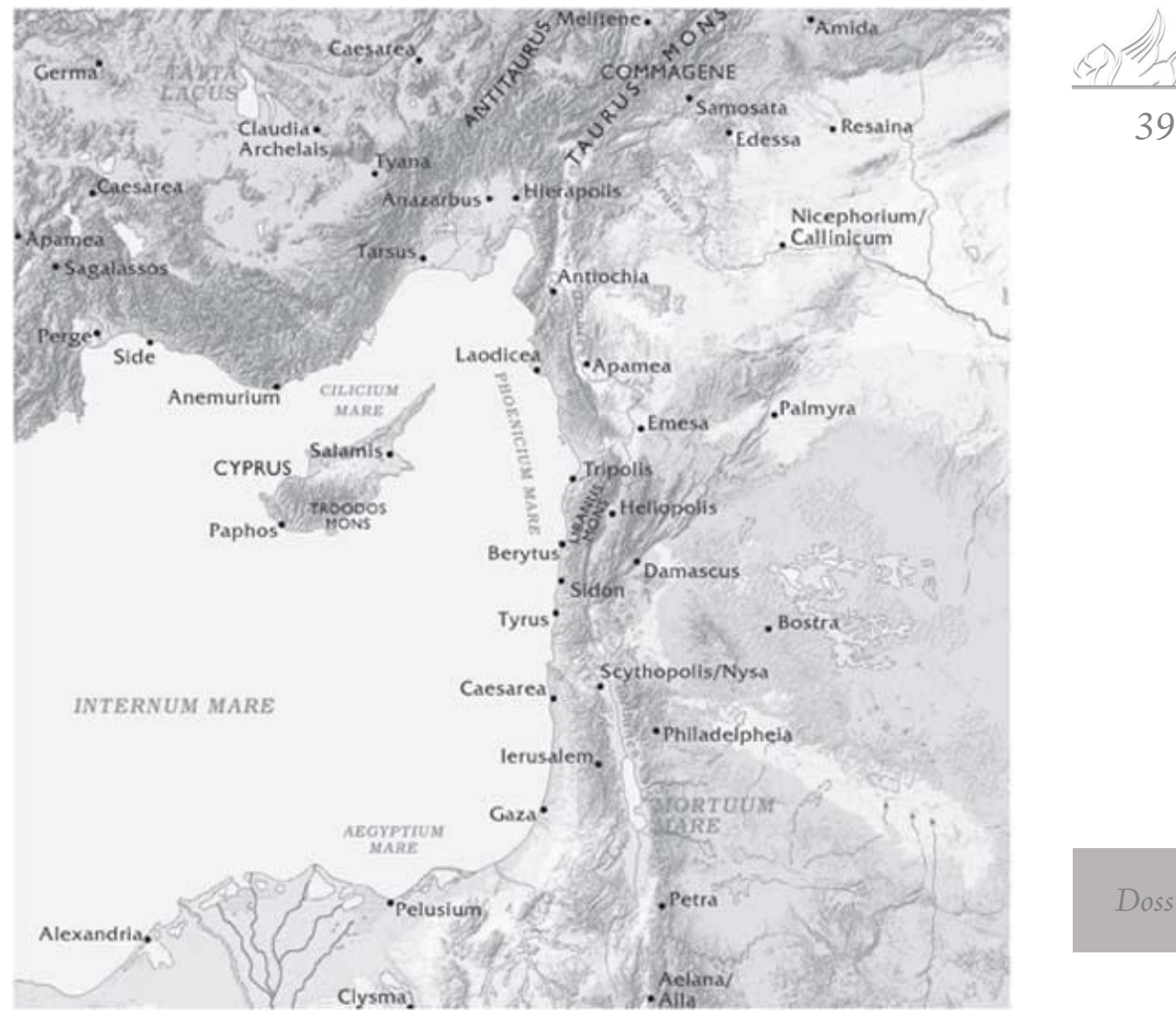

Dossiê

Mapa da região da Síria no Principado Romano

Fonte: ICKS, 2013. Mapa do projeto Ancient World Mapping Center, University of North

Carolina, Chapel Hill, NC.

Ainda que muitos historiadores citem que Júlia Domna advinha da família real de Emesa, especialmente pelo nome de sua sobrinha Júlia Soêmia, Levick (2007) não aceita como certa tal ascendência. ${ }^{11}$ Para essa historiadora, Júlia Domna teria se ligado à família real dinástica ou por usos relacionados ao poder, ou por acreditar que de fato pertencia a uma espécie de realeza local por

11 Sohaemias parece ser o nome semítico (aramaico) usado na tradição epigráfica greco-romana como Soaemias. Dião Cássio e Herodiano grafam o nome como Sohaemis. Tal denominação deve estar ligada ao antigo dinasta de Emesa chamado Sampsigeramus e a seu filho Sohaemus (LEVICK, 2007, p. 5). O nome é encontrado por nós traduzido, tradicionalmente, como Soêmia nos textos em português. A História Augusta (Vida de Heliogábalo, IV, 4) traz a denominação Symiamira para a personagem. Conforme David Magie (1993, p. 106-107), tradutor da História Augusta, essa denominação aparecerá também no texto da Vida de Macrino e a variante Symiasera aparece em um texto de Eutrópio. Para o tradutor esses nomes podem derivar de Simea, uma divindade siríaca. 
vir de uma família de extrema nobreza na cidade. Dessa maneira, não é certeza que Júlia Domna era parte da antiga família real dinástica da cidade.

Podemos ter como certo, então, que a imperatriz vinha de uma importante e rica família de Emesa ligada ao sacerdócio de Elagabal e que esse fato demonstra o enorme prestígio da mesma. Assim, independentemente de ela pertencer ou não à antiga dinastia real emesense, para a sua época romana, conforme os tipos de relaçóes estabelecidas entre imperadores e elites locais, pertencer à nobre família responsável pelo culto a Elagabal era algo que tinha significativo valor. Considero aqui, portanto, que a ligação das famílias aristocráticas provinciais com o poder de Roma, das quais as mulheres eram um elemento fundamental usado em matrimônios, era mais importante do que uma ascendência real antiga. Assim, a forma como a família de Júlia Domna negociou com Roma por meio de seu casamento foi fundamental para sua ascensão dentro do governo imperial.

Hidalgo de la Vega (2012, p. 132) comenta que, também na época de governo do imperador romano Antonino Pio; quando a antiga família real emesense torna-se menos visível na documentação, como citamos acima; temos moedas romanas fazendo referências ao culto de Elagabal. A partir dessa informação, levanto a hipótese de que pode ter ocorrido nesse momento uma ascensão nas relações da família sacerdotal da qual Júlia Domna fazia parte com os romanos, que passam, então, a cunhar moedas com a divindade em homenagem à aliança.

Não muito tempo depois do período de governo de Antonino Pio, em 187, Júlia Domna casa-se com Septímio Severo, então legatus pro praetore, governador da Província da Gália Lugdunense. Antes disso, Severo havia servido Roma como comandante de uma legião na Síria. Severo era viúvo e descendia de uma importante família da cidade de Leptis Magna, na província da África Proconsular. Severo já apresentava um interessante cursus honorum no governo imperial romano e tinha cerca de quarenta anos na época do casamento. Júlia Domna, por sua vez, tinha cerca de treze anos quando é dada em casamento a Septímio Severo.

Sabendo dos entrecruzamentos culturais da região de onde vinha a imperatriz e da importância de seu casamento no estreitamento de laços de sua família com os romanos, passarei agora para uma análise de sua representação nos textos literários que chegaram até nossos dias e de suas possibilidades de atuação política. Na sequência, analisarei as críticas á imperatriz e elemento de sua identidade cultural. 


\section{Júlia Domna e a tradição textual de sua época: uma CONTROVERSA IMPERATRIZ SIRÍACO-ROMANA}

Desde o início do governo de Septímio Severo, Júlia Domna exerceu influência nas decisóes do imperador, atuando de maneira ativa na corte e na administração imperial. Hidalgo de la Vega (2012, p. 159) considera a forma com que Júlia Domna atuou politicamente algo que nenhuma imperatriz havia conseguido antes.

A participação maior de Júlia Domna no poder imperial parece ter ocorrido durante o governo de seu filho Caracala (211-217), cuidando das correspondências e petições do imperador, atendendo homens importantes em recepções públicas, o acompanhando em viagens e campanhas militares, intermediando a nomeação de aristocratas a cargos públicos e sendo a conselheira do filho imperador em assuntos políticos. No entanto, Dião Cássio frisa, em tom de crítica, que ele dificilmente a ouvia.

Nem nesses assuntos, nem em quaisquer outros ele prestou atenção à sua mãe [referindo-se a Caracala e Júlia Domna], que deu a ele muitos conselhos bons. E ainda assim ele havia a designado para receber suas petições e ela tinha a responsabalidade de cuidar de suas correspondências em ambos os idiomas, exceto em casos muito importantes. Ele também costumava incluir o nome dela nos grandes elogios, juntamente com seu próprio nome e os nomes das legióes, bem como em suas cartas para o senado, afirmando sempre que ela estava bem (DIÃO CÁSSIO, História Romana, LXXVIII, 18, 1-3).

É importante perceber que os historiadores Dião Cássio e Herodiano, contemporâneos da imperatriz, serão favoráveis à atuação de Júlia Domna em relação ao governo de Caracala, imperador que ambos são totalmente contrários. ${ }^{12}$ Herodiano (História do Império Romano, III, 15, 8; IV, 3, 8)

12 A imagem de Caracala como mau imperador (pessimus princeps) aparecerá nos textos de Dião Cássio e Herodiano seguindo elementos de um topos retórico dos textos aristocráticos sobre os imperadores para aristocratas como os autores. Sobre Caracala, destacamos, assim, elementos de crueldade cometida em assassinatos sem justificativas de homens das elites tradicionais (homens chamados de ilustres por Dião Cássio), comparação com divindades, falsidades com amigos, perseguição a filósofos, nomeação de homens sem cursus honorum ao senado, gastos desmedidos, muito atenção aos soldados e aos libertos, aumento de impostos, ambição desmedida por dinheiro, gosto por espetáculos artísticos e mesmo por demonstrar habilidades artísticas, selvageria (ferocitas) e desprezo pela educação romana (bumanitas), não ser um bom condutor dos assuntos de guerra e prática desmedida em vários âmbito, como em relação aos cuidados com o corpo, etc. Frisamos, ainda, a maneira como Dião chama Caracala o tempo todo de Antonino, lembrando também que seu nome de nascimento era Basiano, tal como fará ao escrever sobre Heliogábalo, primo de Caracala que Dião Cássio terá como outro modelo de mau governante. Lemos isso como uma relação que o historiador busca fazer entre os dois imperadores considerados ruins na tradição textual, dos quais ele foi contemporâneo. 
mostra a imperatriz sempre em atitudes conciliatórios em relação a Caracala e o irmão Geta, com quem o primeiro dividiu o poder por um ano antes de assassinar o segundo e passar a governar como único imperador.

Aconselhando o filho, sendo ou não ouvida, no entanto é certo que uma das principais formas de atuação da imperatriz foi enquanto patrona de intelectuais, homens aos quais ela ajudou a estabelecer alianças com os imperadores Septímio Severo e Caracala e a receber nomeações. Sobre isso, Filóstrato, sofista e biógrafo também contemporâneo de Júlia Domna, comenta claramente que fez parte de um círculo ( à imperatriz: "E a mim, que pertencia ao seu círculo, visto que ela elogiava e admirava todos os discursos retóricos, ela me encarregou de redigir estes ensaios e me ocupar da sua publicação [...]" (Vida de Apolônio de Tiana, I, 3 ).

Sobre o círculo do qual Filóstrato diz fazer parte, o chamado "círculo de Júlia Domna”, existe uma discussão de estudiosos acerca de sua verdadeira natureza. Os testemunhos documentais sobre o assunto são poucos. Há autores que defendem a existência de um grupo de intelectuais em torno de uma espécie de mecenato da imperatriz, outros duvidam da existência de fato desse círculo. Além da referência na Vida de Apolônio de Tiana, é possível saber da existência desse grupo por meio de outro relato de Filóstrato e de um comentário de seu contemporâneo Dião Cássio. Filóstrato refere-se às afinidades de Júlia em relação à filosofia e relata que Filisco da Tessália se aproximou dos filósofos e matemáticos em torno da imperatriz.

O processo tramitava no tribunal do imperador, que era Antonino, of filho de Júlia [referindo-se a Caracala], dama com afinidades filosóficas. Filisco foi a Roma para resolver seu assunto, aproximou-se dos matemáticos e filósofos que rodeavam Júlia e conseguiu dela a nomeação imperial para a cátedra de retórica de Atenas (Vidas dos Sofistas, II, 622).

Conforme Hidalgo de la Vega (2012, p. 144), com quem concordo, a mencionada concessão à cadeira de retórica em Atenas para Filisco da Tessália mostra um diferencial na potencialidade de Júlia Domna, pois esta era uma decisão apenas dos imperadores. Tal atuação da imperatriz deveu-se, como vemos, à sua vinculação às redes de patronagem imperial em torno do círculo comentado por Filóstrato. ${ }^{13}$ 
Sobre a aproximação da imperatriz com homens devotos ao conhecimento e ensino, Dião Cássio comenta que Júlia Domna se dedicava à filosofia e passava seu tempo com os sofistas como forma de se livrar dos ultrajes que recebia de Plautiano, o prefeito do pretório de Septímio Severo:

Ele [referindo-se a Plautiano] ultrajava Júlia Augusta muitas vezes porque a detestava. Ele estava sempre falando sobre ela para Severo com violência. E ele chegou a fazer investigações sobre sua conduta, bem como tentou reunir provas contra ela torturando mulheres da nobreza. Foi por essa razão que ela começou a estudar filosofia e a passar seus dias em companbia de sofistas (História Romana, LXXVI, 15, 7).

Além da informação sobre a existência de um grupo de intelectuais próximos à imperatriz, pela passagem acima é possível perceber como sua atuação incomodava de alguma forma o prefeito do pretório.

Voltando ao debate sobre o que foi o importante grupo em torno da imperatriz, entre os autores que defendem a existência de um círculo em torno de Júlia está a historiadora Maria Guerrero. Para Guerrero (1994, p. 198), em volta de Júlia Domna circulou um grupo seleto de intelectuais: médicos (Galeno), poetas (Lúcio Septímio Nestor), escritores (Samônico Sereno e, talvez, o grego Cláudio Eliano Prenestino), filósofos (Filóstrato, Frontão de Emesa), juristas (Ulpiano, entre outros), historiadores (Dião Cássio, entre outros), futuros imperadores (o futuro imperador Gordiano frequentou o círculo como poeta), altos funcionários imperiais e outros.

Contudo, Bowersock (1969, p. 103) questiona o renascimento de estilo de corte principesca, argumentando que esse círculo era bem mais limitado e menos expressivo do que alguns pesquisadores citam e que a noção corrente sobre o círculo de Júlia Domna e a lista de seus membros, impossível de ser confirmada com certeza, não passa de uma construção dos estudiosos do século XIX. ${ }^{14}$ Bowersock ainda estranha que os únicos testemunhos que temos sobre esse proeminente círculo sejam as poucas passagens das obras de Filóstrato e uma única menção de Dião Cássio.

O uso da expressão círculo, difundida entre os estudiosos, parece ter surgido da própria expressão usada por Filóstrato na Vida de Apolônio

14 A primeira lista sobre o círculo de Júlia é de 1879, de autoria de Victor Duruy. Em 1907 um novo estudioso listou os intelectuais do círculo: o biógrafo Filóstrato, os juristas Papiano, Ulpiano e Paulo, os historiadores Dião Cássio e Mário Máximo, os médicos Sereno Samônico e Galeno, o poeta Opiano, Gordiano I, Aspásio de Ravena, Antípatro de Hierápolis e Eliano (BOWERSOCK, 1969, p. 102). 


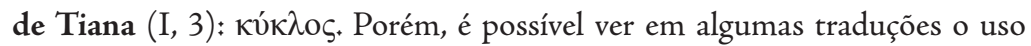
da expressão salão. ${ }^{15}$ Segundo Tim Whitmarsh (2007, p. 34), a ideia de um salão em torno de Júlia (GRANT, 1996) ou corte (ANDERSON, 1986; FLINTERMAN, 1995) está errada e introduz um sentido de falsas confidencias e relações entre Filóstrato e a imperatriz. Whitmarsh completa que não há dúvidas de que Júlia tinha interesses intelectuais e passava seu tempo se dedicando a isso, o que, porém, não significa necessariamente que ela possuía um círculo definido.

Emily Ann Hemelrijk (1999, p. 126), de outra forma, pensa na existência real desse círculo, mas como algo aberto e flexível, formado por um grupo informal de homens que se dedicavam ao conhecimento. Ideia que Hidalgo de la Vega (2012, p. 151) compartilha. Para a segunda historiadora:

É possível que nestas reuniôes abertas, flexíveis e itinerantes, não apenas se discutisse filosofia e literatura, uma vez que seus membros podiam desempenhar cargos políticos. $\mathrm{O}$ círculo, então, adquiriu um significado político e pôde circular em seu seio e nos arredores uma tendência política a favor de Geta, o filho mais novo de Júlia Domna, em quem ela colocou seus interesses de imperatriz e mãe de um herdeiro possível por suas qualidades pacíficas frente à belicosidade de Caracala. Quando Geta morreu, alguns destes personagens desapareceram do círculo por vontade própria ou por castigo imperial (HIDALGO DE LA VEGA, 2012, p. 153).

Diante da discussão apresentada, acredito que há um exagero em pensar que os interesses da imperatriz levaram-na a formar um círculo bem definido, como faz Guerrero (1994). Para mim, esta ideia tem raízes em uma leitura anacrônica da documentação, com olhares para os círculos literários e o mecenato de períodos muito posteriores. Contudo, discordo de Bowersock (1969), que nega a existência do mesmo. Sendo assim, considero como Hemelrijk (1999), Whitmarsh (2007) e Hidalgo de la Vega (2012), que existiram interesses da imperatriz por questóes literárias e filosóficas, assim como sua patronagem em relação a alguns intelectuais, o que a fez rodear-se desses personagens, embora esse círculo fosse algo flexível.

De acordo com Gonçalves (2003, p. 338), as discussóes filosóficas e, especialmente a Segunda Sofística, atraente no final do século II e início do III, podem ter atraído a imperatriz até o final de sua vida. É sabido pela

15 Nas traduções que estamos usando as expressões que aparecem são: salon (salão), na tradução de Cristopher Jones (Loeb Classical Library) e círculo, na tradução de Alberto Barnabé Pajares (Editorial Gredos). 
documentação que a imperatriz teve forte presença nos assuntos públicos, embora de forma indireta. Portanto, não parece estranho que Júlia Domna tenha se interessado pelas discussões intelectuais, o que não deixava de ser algo de enorme valor político para ela e para os homens do grupo.

Devo ressaltar, assim, conforme apresenta Gonçalves (2003, p. 337), que com a existência de um patronato aristocrático que ligava diretamente membros das ricas elites provinciais ao imperador, "as imperatrizes, muitas vezes, intermediavam o acesso dos intelectuais aos governantes, como foi o caso de Júlia Domna". Portanto, as mulheres da família imperial romana tinham uma grande influência no estabelecimento das redes de amizades (amicitia) que envolviam estas relaçóes. Andrew Wallace-Hadrill (1996, p. 303) cita vários exemplos de mulheres da casa imperial Júlio-claudiana nesse aspecto.

Esse foi o caso de Filóstrato, que também se mostrou bem próximo da imperatriz em outras passagens de seu corpus documental, como na Carta 73, endereçada a Júlia Augusta. Essa carta bastante interessante para percebermos as atividades intelectuais da imperatriz, já que nela Filóstrato apresenta elementos sobre literatura e retórica à Júlia Domna, embora haja uma discussão historiográfica sobre a autenticidade e os interesses do autor por trás da escrita da epístola. ${ }^{16}$

Vínculos de patronagem estabelecidos com homens como Filóstrato, que deixaram escritos sobre a imperatriz, bem como as boas relações de governo de seu marido e a tentativa de intermediação entre a elite escritora dos textos na atuação vista como desastrosa de governo do filho, são elementos importantes para que a imagem de Júlia Domna tenha também chegado com forte carga positiva. ${ }^{17}$

No entanto, a imagem de Júlia Domna não é coerentemente positiva nos textos do contexto romano. Seguindo a observação de Gonçalves (2003, p. 346), aquela classificação maniqueísta que comentamos no início deste artigo, entre boas e más imperatrizes não pode ser aplicada para a representação textual de Júlia Domna.

Querida ou odiada, Júlia Domna foi centro de atenção política social e cultural. E, devido a isso, sua imagem se tornou bastante controversa.

16 Sobre tal discussão sugiro a leitura do primeiro capítulo de minha tese de doutorado, intitulada O Império Romano de Filóstrato nas viagens da Vida de Apolônio de Tiana.

17 Os elementos positivos em torno das práticas políticas construídos nos textos sobre Júlia Domna levaram à exaltação também de sua beleza. Curiosamente, em 2001, foi levantada uma hipótese sobre a beleza da imperatriz ter inspirado a famosa estátua da Vênus de Milo (2007, p. 03). 
Vacilava-se entre admirá-la e criticá-la, mas foi uma personagem à qual seus contemporâneos não conseguiram ficar indiferentes (GONÇALVES, 2003, p. 346).

Diante disso, em minha perspectiva, é preciso perceber elementos pouco explorados a identidade cultural da imperatriz em suas representações positivas e também negativas. É sabido que pelo fato de a imperatriz ter vindo de uma região provincial da Síria, membros das elites dessa região tiveram enormes privilégios pelas ligações com sua família, o que pode ter incomodado homens mais tradicionais das elites greco-romanas ou alguns que não se sentiram privilegiados em determinada situação com tais ascensões.

Jean Michel Carrié e Aline Rousselle (1999, p. 49) frisam que com a dinastia severiana, chamado por estes historiadores de eixo africano-sírio, temos de fato provinciais no poder e, por isso, é preciso compreender o que são provinciais, pois com os Severos homens de origens das províncias se firmaram definitivamente em altos postos da administração e da política imperial, como os próprios casos de Dião Cássio e do jurista Ulpiano. É considerável a mudança na própria nobreza dirigente a partir do século II, formada pelas camadas superiores das cidades provinciais, principalmente orientais e a introdução de muitos homens da ordem equestre em cargos antes reservados apenas aos senadores. Gonçalves (1999, p.156) informa, por exemplo, que na época de Heliogábalo 52,5\% dos senadores têm origens provinciais e 57,6 \% deles são das partes orientais do Império, tendo sido postos no senado em promoções realizadas pelo imperador.

Em Dião Cássio, em forma de uma crítica negativa, podemos ler sobre homens dos grupos das elites das províncias do período de Heliogábalo: "[...] alguns que nunca conheceram Roma, vieram para exercer a autoridade tradicional [...]" (História Romana, LXXX, 3, 3). Também podemos ler sobre a entrada de homens sem um cursus honorum tradicional no senado na época de Heliogábalo (História Romana, LXXX, 7, 3-4).

Diante disso, não deve ser considerado estranho que ao criticar Júlia Domna, Dião Cássio use de suas origens siríacas orientais, comentando que ela gostaria de governar Roma após a morte de Caracala aos moldes de lendárias rainhas orientais que governaram soberanas sem estar a sombra de um homem:

E consequentemente, assumiu seu filho de uma maneira mais próxima, pois ela esperava para se tornar a única governante e queria fazer igual à 
As rainhas assírias chamadas na tradição greco-romana como Semíramis e Nitócris são conhecidas, especialmente, pela obra de Heródoto. Nitócris e Semíramis foram, conforme o historiador grego, as duas únicas rainhas a governar a Babilônia, sendo que Nitócris procede Semíramis em cinco gerações. ${ }^{18}$ Em suas descriçóes das rainhas, Heródoto (Histórias, I, 184-187) as apresenta como fortes governantes construtoras de obras que contribuíram para a defesa da Babilônia. Acredito que ao comparar Júlia Domna com estas rainhas, Dião Cássio busca conhecimentos em tradições compartilhadas sobre o poder dessas mulheres, marcando o poder feminino/ oriental de Júlia Domna frente ao governo de sua época.

Assim, é interessante perceber que ao criticar a imperatriz, o historiador que não se mostra contrário a sua atuação em tantas outras passagens, use de sua identidade cultural siríaca/oriental. A mesma coisa Dião Cássio (História Romana, LXXVIII, 10, 2) faz ao criticar Caracala em outra passagem de seu texto, como podemos ler: "Em tudo ele era muito inconstante e tinha a cabeça esquentada. Ele ainda possuía a astúcia de sua mãe e dos Sírios, de onde ele

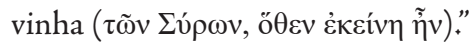

Outro elemento das críticas à imperatriz também diz respeito a construções sobre sua identidade cultural. Como mostra G. Marasco (1996, Apud GONÇALVES, 2003, p. 345), o fato de Júlia Domna ter vindo de regióes orientais, onde o incesto não era tão mal visto como nas províncias ocidentais, pode ter contribuído para a divulgação de boatos em torno de um possível relacionamento afetivo-sexual entre Júlia e seu filho Caracala, citados por Dião Cássio e Herodiano. Assim, fica claro que ao criticar a imperatriz, os textos usaram de sua identidade cultural.

Ainda em relação à identidade siríaca, há estudiosos que defendem que o estilo de cabelo de Júlia Domna era um elemento sírio de sua identidade. ${ }^{19}$ O cabelo tartaruga, que é possível de ser visto em estátuas como a da imagem abaixo e em diversas moedas, era chamado de cabelo em forma de tartaruga, "nos quais os fios são repartidos no meio e cobrem as orelhas, como imitando um casco de tartaruga, terminando num coque. Penteado ou peruca que foi

18 Semíramis também é citada por outros autores como Ctésias de Cnido (Pérsica), Diodoro Sículo (Biblioteca Histórica), Suetônio (Vidas dos Doze Césares, Vida de Júlio César) e Luciano de Samósata (A deusa síria), obras anteriores a de Dião Cássio.

19 Sobre o assunto ver: BAHARAL, 1992. 
muito comum nas primeiras imagens da imperatriz" (GONÇALVES, 2003, p. 349).

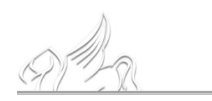

48

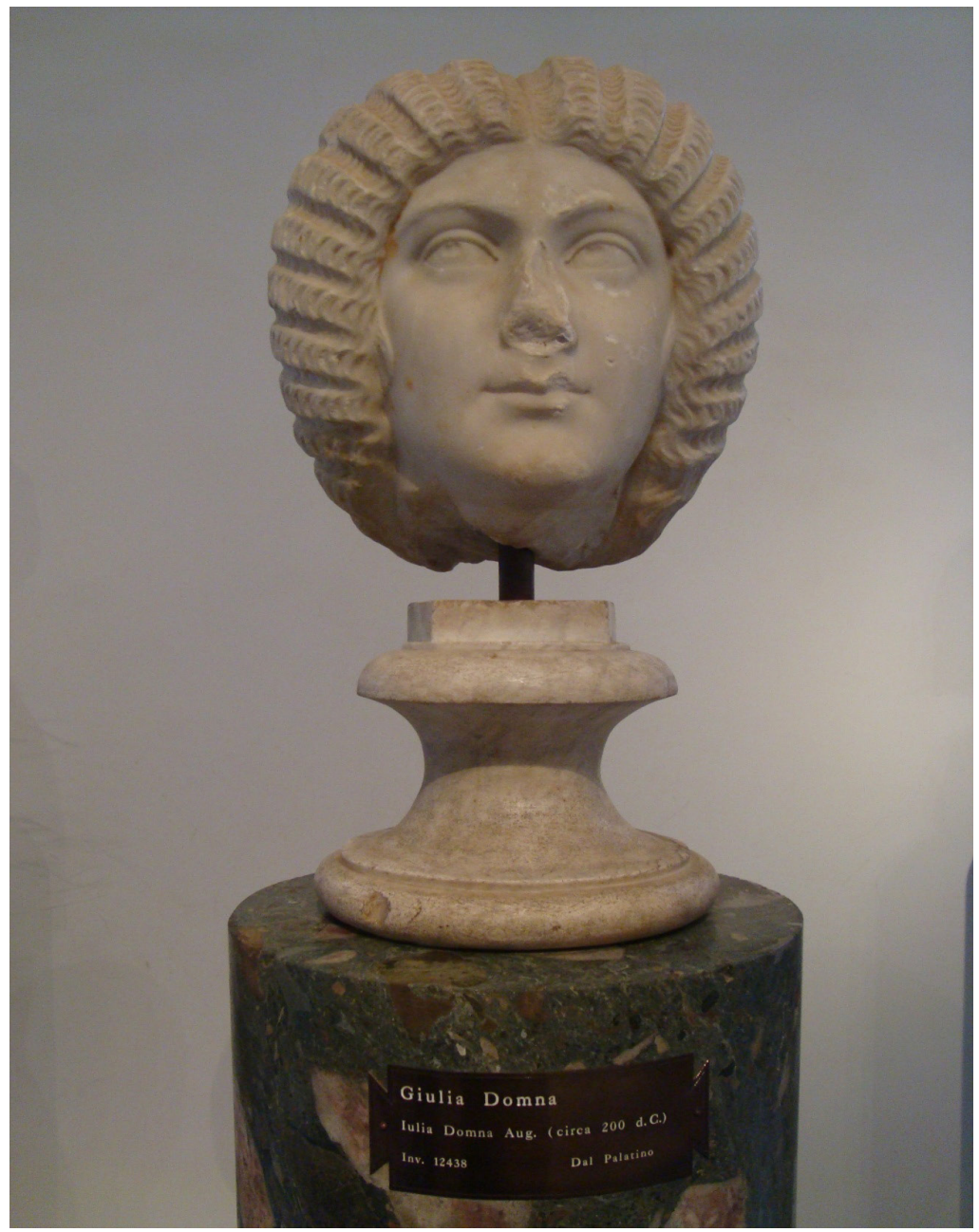

Júlia Domna em estátua datada, aproximadamente, do ano 200. Acervo do Museu Palatino, Roma, Itália.

Fonte: Foto do acervo pessoal da autora, tirada em 04/11/2012.

No entanto, Drora Baharal (1992) argumenta que muitos bustos de Júlia Domna do período de governo de Septímio Severo (193-211) mostram a imperatriz copiando o estilo de cabelo de Faustina, a jovem, filha de Antonino Pio (138-161) e esposa do imperador Marco Aurélio (161-180). Tal elemento 
representa, junto com uma série de outros, os esforços da política imperial severiana em buscar legitimidade na identificação com a gens Aurélia e com a dinastia dos Antoninos. Hidalgo de la Vega (2012, p. 146) concorda que o estilo de penteado de Júlia Domna não foi uma novidade trazida por ela. Segundo essa historiadora, o cabelo da imperatriz severiana já tinha sido usado por Brutia Crispina, esposa de Cômodo (180-192), embora tenha sido Júlia Domna que o deixou conhecido, havendo características orientais nele, características que, entretanto, Hidalgo de la Vega não comenta quais eram. ${ }^{20}$

Hiesinger (1969) ao estudar o retrato de Júlia Domna em um rosto de bronze encontrado na região da Síria, o Fogg Portrait, defende que, embora haja um estilo de representação muito romano no retrato, há elementos orientais na representação da imperatriz produzida fora de Roma, o que não acontecia em seus retratos romanos. $\mathrm{O}$ rosto tende a ser mais largo, as bochechas mais inchadas, dando o sentido de uma estrutura mais articulada. O cabelo é maior, mais geométrico e mais padronizado com o rosto. Esse estilo, defende o estudioso (1969, p. 44), dava outra espiritualidade para a imperatriz e é um exemplo de um retrato de personagens da política romana produzidos no Oriente. A imperatriz é mostrada com um sorriso suave, ainda jovem e com ares de nostalgia, apresentado certa simpatia do artista com ela. Hiesinger defende também que o Fogg Portrait é uma representação mais tardia de Júlia Domna.

Voltando ao cabelo da imperatriz, a relação de seu estilo com a identidade siríaca não parece ter sido grande problema para os autores que não fizeram uso desse elemento ao criticá-la. Críticas não diretas ao cabelo da imperatriz parecem ter vindo dos cristãos Tertuliano (Sobre o vestuário das mulheres, 2, 7) e Clemente de Alexandria (O pedagogo, 3, 11), mas nesse caso fazendo referências a ideias para as mulheres cristãs.

Entretanto, apesar das críticas mostradas, a representação de Júlia Domna é mais positiva do que negativa na documentação textual. Diante disso, cumpre mencionar que estou corroborando uma historiografia que percebe a existência de uma cultura das elites no Império Romano, formada especialmente por elementos culturais gregos e romanos em interação. Seguindo esta historiografia, defendo que durante o Império foi construída uma identificação greco-romana entre os grupos privilegiados que foi um fator

\footnotetext{
20 Heinsiger (1969) nos atenta para o fato de haver uma classificação dos estudos sobre o estilo de cabelo de Júlia Domna em duas fases: a segunda fase é de retratos produzidos, no entanto, primeiro, entre 193 e 211. Já a primeira fase, é conhecida especialmente pelos retratos das moedas e seria do período de 211-217. No entanto, o mesmo estudioso acredita ser muito difícil distinguir essas duas fases tão claramente nas representações.
} 
de coesão e ordem no mundo imperial romano. No entanto, as culturas dentro do Império eram plurais e em cada região tal cultura de elite se hibridizava de diferentes formas e ritmos. Dentre os historiadores que trabalham com a mesma percepção cito Greg Woolf (1998), Janet Huskinson (2000) e Andrew Wallace-Hadrill (2008), por exemplo.

Nesse sentido, percebo que os textos que chegaram para nós irão frisar imagens de governantes como bons ou ruins conforme eles se aproximam desse fator de coesão e ordem imperial que era a cultura greco-romana das elites. Júlia Domna, ao que me parece, soube se articular bem diante desse importante elemento da ordem romana. Mesmo que sua cultura siríaca da imperatriz permanecesse de alguma forma em seu modus vivendi, ela soube se aproximar desses valores culturais que sustentavam a governabilidade e que foram essenciais para a afirmação dinástica dos Severos.

O conhecimento de latim e grego da imperatriz, por exemplo, nunca foi colocado à prova como foi o acento púnico de seu marido Septímio Severo (KEMEZIS, 2006, p. 38), o que demonstra seus esforços e seu papel chave na política dinástica severiana frente aos grupos mais tradicionais e à ordem imperial.

Ao que me parece, os intelectuais que a circulavam tiveram papel importante nessa imagem greco-romana da imperatriz. Filóstrato é o escritor que melhor nos mostra isso, tanto a apresentando como uma leitora de sofistas gregos (Carta 17), como transformando Apolônio de Tiana, seu biografado, em um legítimo sacerdote de uma divindade solar helênica e aceitável (Vida de Apolônio de Tiana). Sobre Apolônio como sacerdote de uma divindade solar, defendo, em outro texto de minha autoria, que a personagem histórica de Apolônio de Tiana foi possivelmente recriada por seu biógrafo como sacerdote de uma divindade solar chamada de Hélio como forma de helenizar o culto de Elagabal que os Severos trouxeram para Roma e torná-lo mais aceitável aos modelos culturais defendidos pelas elites mais tradicionais. ${ }^{21}$

No entanto, ainda que tenha havido um esforço dos escritores e da política severiana na construção de uma imagética da imperatriz como próxima dos valores culturais da ordem imperial, sabemos que eles a criticavam usando de sua cultura siríaca, o que aponta para uma possível imperatriz que mantivesse presente suas tradições de origem. Além disso, Levick (2007, p. 22) nos aponta um exemplo da cultura material que nos chegou que pode trazer indícios da mulher síria que era Júlia Domna era. Trata-se de um relevo do Arco dos

21 Trata-se do texto Cultuando divindades solares: Apolônio de Tiana versus Heliogábalo (século III EC), no prelo. 
Argentários, no Fórum Boário, onde Domna é mostrada com o vestido sem os marcados adornos das roupas das matronas romanas e no seu gesto, com a mão direita levantada e com a palma da mão para frente. Nesta imagem, conforme a historiadora citada, ecos orientais foram vistos por estudiosos em comparação à estátua de uma jovem da dinastia real de Hatra (238 EC).

No entanto, é preciso considerar que diferentes elementos de identidades culturais podiam conviver em um mesmo indivíduo sem problemas nesse período, como nos mostra Greg Woolf (1994). Dessa forma, Júlia Domna como imperatriz pôde ter mantido elementos sírios em suas vestimentas, cabelo, etc., ainda que conforme os usos políticos necessários fosse ressaltada e usada sua aproximação com a cultura greco-romana.

Por fim, Júlia Domna não poderia ter tido histórias menos dramáticas em torno de sua morte frente ao seu papel político e à complexidade da construção de sua imagem. Dião Cássio (História Romana, LXXIX, 23) conta que em 217, quando the chegou a notícia do assassinato de Caracala, ela, que se encontrava em Antioquia, tentou passar fome até morrer. Mas seu sentimento naquele momento não era de tristeza, pois ela odiava o filho, ela não queria era ter que sair dos trâmites políticos imperiais, já que não teria mais o filho imperador que amparava sua posição. No entanto, desejosa de poder Domna acaba colocando de lado a vontade de morrer e começa um complô com os soldados para se tornar a governante, ao modelo das mulheres assírias. Nesse momento há um problema na documentação de Dião Cássio e faltam informações. Dião, nos trechos que seguem e que nos chegaram, escreve que ela pode ter morrido de um tumor no seio já antigo que inflamou por ocasião da notícia da morte do filho. Herodiano (História do Império Romano, IV, 13, 8), por sua vez, conta que Júlia Domna se suicidou após receber de Macrino, o prefeito do pretório e próximo imperador romano, as cinzas de Caracala para que fossem cumpridos os ritos fúnebres.

A construção da imagem de Júlia Domna, entretanto, não acaba com sua morte, ela continuará na Antiguidade Tardia com toda carga de densidade que envolve a personagem, o que, entretanto, não caberia tratar neste texto por envolver novos problemas em um novo contexto.

\section{CONSIDERaÇões Finais}

Embora tenhamos tantas representaçóes de Júlia Domna em textos, moedas, pinturas, relevos, estátuas e joias, Levick (2007, p. 04) traz alguns questionamentos sobre a personalidade e a cultura da imperatriz que podem 
fazer dela uma personagem extremamente enigmática, conforme analisei neste artigo. Assim, refletindo a partir de alguns questionamentos trazidos pela historiadora citada, termino esse artigo como mais perguntas do que respostas, o que não deixa de ser comum na reflexão sobre a Antiguidade, que chega para nós em documentos fragmentários, enviesados por lutas e juízos de valores e, especialmente, trazendo raros ecos de vozes de mulheres.

Diante disso, como elementos da cultura siríaca permaneciam incorporados na imperatriz romana e o quanto exótica ela de fato podia ser aos olhos dos escritores? Ainda assim, o quanto estes escritores podem não ter destacado os elementos sírios de sua identidade cultural por conta de serem favoráveis ao papel que ela exerceu nos governos de seu marido e filho? $\mathrm{O}$ quanto eles defenderam uma Júlia Domna greco-romana por ela ter cumprido seu papel de matrona e estabelecido vínculos entre estes escritores, políticos e os imperadores? O quanto Júlia Domna trazia de fato da cultura greco-romana das elites? O quão adaptada ela de fato esteve ao cenário da ordem grecoromana imperial? $\mathrm{E}$, mais que isso, o quanto ela hibridizou elementos siríacos e greco-romanos para afirmar sua dinastia no poder e trazer para Roma o poder da cidade de Emesa?

Ao que me parece, então, os autores usaram e abusaram da identidade greco-romana da imperatriz quando lhes convinha defendê-la e, da mesma forma, puderam frisar sua cultura síria quando ousaram criticá-la.

Para encerrar as reflexóes deste texto, ainda que o artigo tenha buscado salientar os aspectos de poder e a importância política de Júlia Domna, devo ressaltar que percebo uma tendência contemporânea de pensar personagens históricas de mulheres que aparecem com destaque na documentação antiga, como Cleópatra, por exemplo, como totalmente empoderadas. Tal visão não percebe o quanto tais mulheres aristocratas também estiveram limitadas a elementos culturais de sua época, como o casamento e seus significados políticos. Esse me parece ter sido o caso de Júlia Domna e também de Cleópatra. No entanto, é preciso também pensar estas mulheres enquanto sujeitos dentro destas estruturas, percebendo, da mesma maneira, como elas conseguiram negociar dentro dos limites estabelecidos.

Dessa maneira, em uma história de sociedades construídas com bases misóginas, o papel das mulheres precisa ser minuciosamente complexificado. Para tanto, é necessário trazê-las para a escrita histórica de forma problematizadora, analisando como elas puderam agir enquanto sujeitos históricos dentro de determinados contextos restritivos, considerando o que podiam subverter, por um lado, e o que reproduziam, por outro. 
Além disso, também é preciso complexificar os testemunhos sobre as mulheres que nos foram deixados, suas intenções no entremeio de relações de força e poder. Nesse sentido, para mim, Júlia Domna podia ser bem menos greco-romana como os textos buscaram mostrá-la, daí as críticas usarem de sua identidade cultural não greco-romana para tecer sua imagem negativa quando necessitaram. Ainda que de forma diferente pelas questões do jogo imperador/ aristocracia tradicional, elementos da construção identitária também foram usados pelos mesmos escritores que trabalhamos em relação à Júlia Domna ao construírem a imagem de seu sobrinho-neto Heliogábalo, imperador romano entre 218 e 222. Mas, essa é outra história da interessante dinastia severiana.

\begin{abstract}
From the end of the second century CE, a noble family from the city of Emesa, in Syria, ascended in the Roman imperial administration through the marriage of Julia Domna with the general Septimius Severus, made emperor years later, in 193. From then, the power of the next Roman emperors, members of the Severan dynasty (193-235), will be transmitted matrilinearly. After Julia Domna, her sister Julia Maesa will have great power under the policy and imperial rule of the grandsons Heliogabalus (218-222) and Severus Alexander (222-235). Similarly, Julia Soaemias and Julia Mamaea, mothers of Heliogabalus and Severus Alexander, respectively, had power in the Roman government. In this sense, Julia Domna had a fundamental importance in the dynastic continuation and prominence in the governments of her husband Septimius (193-211) and his son Caracalla (211-217). This study intends to approach elements of the power of Julia Domna, presenting its possibilities of action as empress. In the same way, I would like to analyze the elements of Julia Domna's cultural identity in relation to the negative critics of the empress in texts from the Roman context.
\end{abstract}

Keywords: Roman Empire; Severan dynasty; Julia Domna; Emesa.

\title{
REFERÊNCIAS
}

\section{Documentação}

BÍBLIA DE JERUSALÉM. São Paulo: Paulinas, 1995.

CASSIUS DIO. Dio's Roman History. Vol. IX. Traduzido por Earnest Cary. London/Harvard: William Heinemann/Harvard University Press, 1995.

CLEMENTE DE ALEXANDRIA. El pedagogo. Introducción por Ángel Castiñeira Fernández. Traducción y notas por Joan Sariol Diaz. Madrid: Gredos, 1988.

FILÓSTRATO, F. Vida de los sofistas. Traduções do grego e notas por Antonio Sanz Romanillos, José Ortiz y Sanz y José M. Riaño; prólogo general por Juan Martín Ruiz-Werner; preámbulos parciales por F. de P. Samaranch y J.M. Riaño. In: FILÓSTRATO, EUNAPIO. Biógrafos griegos. Madrid: Aguilar, 1973, p. 1389-1456. 
. Vida de Apolônio de Tiana. Tradução, introdução e notas de Alberto Bernabé Pajares. Madrid: Editorial Gredos, 1979.

. Heroico, Gimnastico, Descripciones de Cuadros, Cartas. Introducción

de Carles Miralles. Tradução e notas de Francesca Mestre. Madrid: Editorial Gredos, 1996.

PHILOSTRATUS. The Life of Apollonius of Tyana. Editado e traduzido por Cristopher P. Jones. Cambridge/Massachusetts/London: Harvard University Press, 2005, Vol. I.

. The Life of Apollonius of Tyana. Editado e traduzido por Cristopher P. Jones. Cambridge/Massachusetts/London: Harvard University Press, 2005, Vol. II.

HERODIANO. Historia del Imperio Romano después de Marco Aurélio. Traducción y notas por Juan J. Torres Esbarranch. Madrid: Editorial Gredos, 1985.

HERÓDOTO, Livro I - Clio. In: . Histórias. Tradução de J. Brito Broca. São Paulo: Ediouro, 2001, p. 43-184.

SCRIPTORES. Histoire Auguste. Tome III, 1re partie: Vies de Macrin, Diaduménien et Héliogabale. Texto estabelecido, traduzido e comentado por R. Turcan. Paris: Les Belles Lettres, 2002.

TERTULIANO. A moda feminina. Tradução de Fernando Melro. Lisboa: Verbo, 1974.

\section{Referências bibliográficas}

ANDERSON, G. Philostratus: Biography and Belles-Lettres in the Third Century A.D. London/Dover: New Hampishire, 1986.

BAHARAL, D. The Portraits of Julia Domna from the years 193-211 A.D. and the Dynastic Propaganda of L. Septimius Severus, Latomus, T. 51, Fasc. 1, 1992, p. 110-118.

BOWERSOCK, G. W. Greek Sophists in the Roman Empire. Oxford: Clarendon Press, 1969.

BUSTAMANTE, R. M. C. Práticas culturais no Império Romano: entre a unidade e a diversidade. In: SILVA, G. V.; MENDES, N. M. (Orgs.). Repensando o Império Romano. Perspectiva socioeconômica, política e cultural. Rio de Janeiro/Vitória: Mauad/EDUFES, 2006, p. 109-133.

CARRIÉ, J-M.; ROUSSELLE, A. L'Empire Romaine en mutation. Des Sévères à Constantin. 192-337. Paris: Éditions du Seuil, 1999.

FINLEY, M. As mulheres silenciosas de Roma. In: Aspectos da Antiguidade. São Paulo: Martins Fontes, 1991, p.149-164.

FLINTERMAN, J. J. Power, Paideia \& Pythagoreanism: Greek identity, conceptions of the relationships between philosophers and monarchs and political ideas in Philostratus' Life of Apollonius. Amsterdam: J. C. Gieben, 1995.

GONÇALVES, A. T. M. Heliogábalo: Culto Oriental e Oposição Senatorial. História (São Paulo), São Paulo, v. 19, 1999, p.147-159.

.Um olhar sobre Julia Domna. Esposa e mãe de Imperadores. In: FUNARI, P. P. A.; SILVA, G. J.; FEITOSA, L. M. Amor, desejo e poder na Antiguidade. Relações de gênero e representações do feminino. Campinas: Editora da UNICAMP, 2003, p. 327-353.

GRANT, M. The Severans. The changed Roman Empire. London: Routledge, 1996. 
GUERRERO, M. D. S. El mecenazgo femenino imperial: el caso de Julia Domna, L'Antiquité Classique, Bruxelles, Tome LXIII, 1994, p. 193-200.

HEMELRIJK, E. A. Matrona docta: educated women in the Roman élite from Cornelia to Julia Domna. London/ New York, 1999.

HIDALGO DE LA VEGA, M. J. Las emperatrices romanas. Sueños de púrpura y poder oculto. Salamanca: Ediciones Universidad de Salamanca, 2012.

HIESINGER, U. W. Julia Domna: two portraits in bronze, American Journal of Archaeology, 73, n. 1, 1969, p. 39-44.

HUSKINSON, J. Looking for culture, identity and power. In: HUSKINSON, J. (ed.). Experience Rome. Culture, identity and Power in the Roman Empire. New York: Routledge, 2000, p. 03-27.

. Elite culture and the identity of Empire. In: HUSKINSON, J. (ed.).

Experience Rome. Culture, identity and Power in the Roman Empire. New York: Routledge, 2000, p. 95-123.

ICKS, M. The crimes of Elagabalus. London/New York: I. B. Taurus, 2013.

LEVICK, B. Julia Domna. Syrian Empress. London/New York: Routledge, 2007.

LIVERANI, M. Antigo Oriente. História, sociedade e economia. São Paulo: EDUSP.

MILLAR, F. The problem of Hellenistic Syrian. In: KUHRT, A.; SHERWINWHITE, S.; Hellenism in the East. The Interaction of Greek and Non-Greek Civilizations from Syria to Central Asia After Alexander. London: Duckworth, 1997, p.110-133.

ROUSSELLE, A. A política dos corpos entre procriação e continência em Roma. In: DUBY, G.; PERROT, M. História das Mulheres no Ocidente, vol. 01. Porto: Ed. Afrontamento, 1990, p. 351-406.

SILVA, S. C. Mulher e casamento em Roma: considerações sobre a matrona Pudentila. In: CÂNDIDO, M. R. (Org.). Mulheres na Antiguidade: Novas Perspectivas e Abordagens. 1ed. Rio de Janeiro: UERJ/NEA, 2012, v. 1, p. 332-346.

. O Império Romano de Filóstrato nas viagens da Vida de Apolônio de Tiana. Tese de Doutorado defendida na UNESP/Franca, 2014.

- A corrupção e os crimes de Heliogábalo: aspectos da governabilidade imperial romana e as práticas políticas do princeps sírio vistas por seus detratores (século III EC) In: SILVA, S.C; CAMPOS, C. E. C. (Orgs.). Corrupção, crimes e crises na Antiguidade. Rio de Janeiro: Desalinho/CNPq, 2018, p. 193-216.

VENTURINI, R. L. B. Amizade e política em Roma: o patronato na época imperial, Acta Scientiarum, Maringá, 23(1), 2001, p, 215-222.

VEYNE, P. O inventário das diferenças. História e Sociologia. São Paulo: Brasiliense, 1983.

WALLACE-HADRILL, A. Rome's Cultural Revolution. Cambridge/New York: Cambridge University Press, 2008.

WHITMARSH, T. Prose literature and the Severan dynasty. In: SWAIN, S.; HARRISON, S.; ELSNER, J. SWAIN, S. (edits.). Severan Culture. Cambridge: Cambridge University Press, 2007, p. 29-51.

WOOLF, G. Becoming roman, staying greek: Culture, identity and civilizing process in the Roman East, PCPhs, 40, p. 116-143, 1994.

- Becoming Roman. The origin of provincial Civilization in Gaul. Cambridge: Cambridge University Press, 1998. 